\title{
BiPAP in Early Guillain-Barré Syndrome May Fail
}

\author{
Eelco F.M. Wijdicks, Tuhin K. Roy
}

\begin{abstract}
Background: Non-invasive mechanical ventilation (BiPAP) has been introduced for use in neuromuscular respiratory disease such as amyotrophic lateral sclerosis and myasthenia gravis. There is no experience in Guillain-Barré syndrome. Methods: We describe for the first time the use of BiPAP to assist in the work of breathing in two consecutive patients with progressing Guillain-Barré syndrome (GBS) and marginal pulmonary function. Results: Our initial attempts to use BiPAP in GBS and early neuromuscular respiratory failure were totally unsuccessful. There was marked initial improvement; however, emergency intubation was needed in both patients, one of which became acutely cyanotic. Conclusions: Until more experience is available, we strongly warn against using BiPAP in deteriorating patients with GBS.
\end{abstract}

RÉSUMÉ: Le système BiPAP peut échouer dans le syndrome de Guillain-Barré en phase précoce. Contexte:
La ventilation mécanique non effractive (BiPAP) est utilisée dans les maladies neuromusculaires avec atteinte
respiratoire comme la sclérose latérale amyotrophique et la myasthénie grave. Cependant, il n'y a pas de données
sur le syndrome de Guillain-Barré (SGB). Méthodes: Nous décrivons pour la première fois l'utilisation du BiPAP
pour fournir une assistance respiratoire chez deux patients consécutifs présentant un (SGB) évolutif et une fonction
pulmonaire limite. Résultats: Nos premières tentatives d'utilisation du BiPAP dans le SGB avec insuffisance
respiratoire neuromusculaire au début se sont soldées par un échec. L'amélioration initiale était importante,
cependant une intubation d'urgence s'est avérée nécessaire chez les deux patients, dont un est devenu subitement
cyanosé. Conclusions: Tant qu'il n'y a pas plus de données à ce sujet, nous décourageons fortement son utilisation
chez les patients atteints d'un SGB évolutif.

Can. J. Neurol. Sci. 2006; 33: 105-106

Non-invasive mechanical ventilation using bilevel positive airway pressure provides cycles of pressure-support ventilation in the inspiratory phase and positive end-expiratory pressure in the expiratory phase. Bilevel positive airway pressure has emerged as an alternative to endotracheal intubation and mechanical ventilation in primary pulmonary disorders. ${ }^{1}$ Concern about the morbidity of mechanical ventilation has resulted in increased use of BiPAP. In acute neurologic diseases, BiPAP can provide ventilatory assistance in myasthenic crises while awaiting the effect of plasma exchange. ${ }^{2}$ Nasal mask continuous positive air pressure has been used in patients with bilateral diaphragmatic paralysis after heart surgery and one successful attempt to prevent intubation is on record in GuillainBarré syndrome. ${ }^{3,4}$ Neuromuscular respiratory failure is present in $30 \%$ of patients with Guillain-Barré syndrome. In patients with marginal respiratory function who are not necessarily candidates for immediate intubation, BiPAP could theoretically be a useful, temporary assisting device. The decreased workload of breathing leads not only to marked improvement in patient comfort but also to improved gas exchange. We have recently used BiPAP in two patients with Guillain-Barré syndrome but report its failure, and worse, emergency intubation in both of these patients.

\section{Patients}

\section{Case 1}

A 52-year-old priest was admitted with progressive weakness that had progressed over two days with inability to stand (MRC 3/5). Nerve conduction studies showed reduced and absent motor and sensory responses with sporadic fibrillation potentials. Cerebrospinal fluid (CSF) showed $56 \mathrm{mg} / \mathrm{dl}$ and one cell/mcL. He was treated with intravenous gamma globulin (IVIG); and after the second day of infusion, he noted respiratory discomfort. On examination, his respiratory rate was increased to 22 breaths per minute and, subjectively, he felt he was "working to breathe." There was no new oropharyngeal weakness. His PiMAX was - $62 \mathrm{~cm} \mathrm{H}_{2} \mathrm{O}$; PeMAX was $60 \mathrm{~cm} \mathrm{H}_{2} \mathrm{O}$ and his vital capacity varied between 800 to $1200 \mathrm{ml}$. Arterial blood gas was

From the Department of Neurology, Division of Critical Care Neurology (EFMW), Department of Anesthesiology, Division of Critical Care Medicine (TKR), Mayo

Clinic College of Medicine, Rochester, Minnesota, USA.

ReCEIVEd MAY 20, 2005. ACCEPTED In FinAl fORM August 27, 2005 Reprint requests to: Eelco F.M. Wijdicks, Mayo Clinic College of Medicine, Department of Neurology, W8B, 200 First Street SW, Rochester, Minnesota 55905 USA. E-mail:wijde@mayo.edu. 
normal with a pH 7.39; arterial $\mathrm{PO}_{2}$ of $91 \mathrm{mmHg}$; arterial $\mathrm{PCO}_{2}$ of 45 $\mathrm{mmHg}$; and a bicarbonate of $27 \mathrm{mEq} / \mathrm{L}$. He was admitted to the neurological-neurosurgical intensive care unit and started on BiPAP (IPAP of 14 and EPAP of eight with five liters oxygen per minute), which led to immediate subjective improvement with tidal volumes around $700 \mathrm{ml}$. Following the initiation of BiPAP the arterial blood gas showed a $\mathrm{pH}$ of 7.42; arterial $\mathrm{PO}_{2}$ of $108 \mathrm{~mm} / \mathrm{Hg}$; arterial $\mathrm{PCO}_{2}$ of 37 $\mathrm{mm} / \mathrm{Hg}$ and serum bicarbonate of $25 \mathrm{mEq} / \mathrm{L}$. Oxygenation and blood gas remained normal for five hours. He suddenly deteriorated with an acute hypoxemia and cyanosis leading to emergency intubation and mechanical ventilation using intermittent mandatory ventilation and pressure support. Vital capacity was $500 \mathrm{ml}$, and PiMAX and PeMAX after intubation were respectively -10 and $15 \mathrm{~cm} \mathrm{H}_{2} \mathrm{O}$ despite good effort. Chest $\mathrm{x}$-ray did not show any evidence of a recent aspiration. The time from onset of paresthesias to respiratory intubation was five days. He had a prolonged course, including tracheostomy and mechanical ventilation for $2 \frac{1}{2}$ months but made a full recovery within 18 months.

\section{Case 2}

A 79-year-old woman was admitted after a two-day progression of diplopia and full ophthalmoplegia and marked imbalance. The next day her symptoms progressed with weakness in upper and lower extremities (MRC 4/5). When she was transferred to the neurological-neurosurgical intensive care unit, she was breathing comfortably, but her respiratory rate was around 20 breaths per minute with notable shallow tidal volumes. She coughed frequently during conversations. The initial PiMAX was $-24 \mathrm{~cm} \mathrm{H}_{2} \mathrm{O}$ with a vital capacity of one liter. On further neurological examination, she had a complete ophthalmoplegia, bilateral ptosis, and facial diplegia but had normal oropharyngeal strength. There was a quadriparesis (MRC 3/5) and generalized areflexia. She was placed on BiPAP and for ten hours was comfortable with the settings IPAP of eight and EPAP of four on room air. The arterial blood gas while on BiPAP was $\mathrm{PH}$ of 7.45; arterial $\mathrm{PCO}_{2}$ of $30 \mathrm{mmHg}$; and arterial $\mathrm{PO}_{2}$ of $86 \mathrm{mmHG}$ with room air. Her oxygenation and blood gas remained normal. She suddenly deteriorated with marked hypoxemia and pulse oximetry saturations in the 80 s. Oxygen saturation minimally improved on $40 \%$ oxygen, and she remained tachypneic at 30 breaths/minute. She was intubated and mechanically ventilated with intermittent mandatory ventilation and pressure support. After intubation a PiMAX of $5 \mathrm{~cm} \mathrm{H}_{2} \mathrm{O}$ PeMAX of $5 \mathrm{~cm} \mathrm{H}_{2} \mathrm{O}$ with a vital capacity of $700 \mathrm{~mL}$ was recorded. The time from diplopia to endotracheal intubation was three days. She reached a plateau after IVIG treatment and showed early signs of motor improvement 13 days after onset.

\section{Discussion}

Our initial attempts to use BiPAP in two consecutive patients with Guillain-Barré syndrome and early neuromuscular respiratory failure were totally unsuccessful. At the start both patients had marked improvement with the use of BiPAP, and we were able to measure very satisfactory tidal volumes. The acute clinical onset of respiratory failure was impressive but correlated with a rapid quantifiable decline in pulmonary mechanics.

The false sense of security with both patients-on BiPAP for several hours only to deteriorate acutely leading to emergency intubation -- is distressing. Although the decision to intubate both patients can be questioned, we felt the marked sudden respiratory failure precluded further experimentation with higher biplane BiPAP levels. Acute hypoxemia could be due to excessive secretions obstructing the airway, use of opioids to control pain, or - more likely in our patients with good oropharyngeal function - due to a VQ mismatch as a result of microatelectasis. This is likely a reflection of the rapid decline in pulmonary mechanics. Patients with Guillain-Barré syndrome, particularly in a progressive phase, can rapidly develop neuromuscular respiratory failure. We have noted in an earlier study that respiratory mechanics may decrease more than $80 \%$ in patients since admission and some of them are unable to build up adequate force or generate an adequate tidal volume..$^{5}$ In addition, a rapid beneficial effect of plasma exchange or IVIG is rarely seen in Guillain-Barré syndrome with respiratory failure. Emergency intubation is uncommon in Guillain-Barré syndrome $^{6}$ and our patients are the first such patients requiring emergency intubation at our institution in 15 years.

Therefore, could we have a priori expected failure in acute neuromuscular disease in GBS? In these patients non-invasive ventilation may be problematic for many reasons. Many patients with GBS have marked oropharyngeal dysfunction, which results in pooling of secretions. Non-invasive ventilation could produce thickened secretions due to loss of water vapor; and with full face masks, there is an additional risk of aspiration. ${ }^{7}$

Bilevel positive airway pressure is increasingly promoted in the emergency department and recently suggested by one case experience, but we would warn against its indiscriminate use in Guillain Barré syndrome and call for a prospective study. ${ }^{4,8}$ There is no systematic study on the use of BiPAP in weaning of patients with Guillain-Barré syndrome nor its use in patients with less rapid deterioration in weakness. In the acute phase of GBS, it is likely that the involvement of the diaphragm and other inspiratory muscles are of such a severity that only volumetriggered ventilation can adequately support these patients. Although not a concern in our cases, poor synchronization with the device during rapid shallow breathing and pooling of secretion from oropharyngeal weakness may also complicate use of BiPAP.

\section{REFERENCES}

1. Yosefy C, Hay E, Ben-Barak A, et al. BiPAP ventilation as assistance for patients presenting with respiratory distress in the department of emergency medicine. Am J Respir Med. 2003;2:343-7.

2. Rabinstein A, Wijdicks EF. BiPAP in acute respiratory failure due to myasthenic crisis may prevent intubation. Neurology. 2002;59:1647-9.

3. Tokuda Y, Matsumoto M, Sugita T, et al. Bilateral diaphragmatic paralysis after aortic surgery with topical hypothermia: ventilatory assistance by means of nasal mask bilevel positive pressure. J Thorac Cardiovasc Surg. 2003;125:1158-9.

4. Pearse RM, Draper A, Grounds RM. Non-invasive ventilation to avoid tracheal intubation in a patient with Guillain-Barre syndrome. Br J Anaesth. 2003;91:913-6.5. Lawn ND, Wijdicks EF. Post-intubation pulmonary function test in GuillainBarre syndrome. Muscle Nerve. 2000;23:613-6.

5. Lawn ND, Wijdicks EF. Post-intubation pulmonary function test in Guillain-Barre syndrome. Muscle Nerve. 2000;23:613-16.

6. Wijdicks EF, Henderson RD, McClelland RL. Emergency intubation for respiratory failure in Guillain-Barre syndrome. Arch Neurol. 2003;60:947-8.

7. Elliott MW. Non-invasive ventilation for acute respiratory disease. Br Med Bull. 2004;72:83-97.

8. Poponick JM, Renston JP, Bennett RP, Emerman CL. Use of a ventilatory support system (BiPAP) for acute respiratory failure in the emergency department. Chest. 1999;116:166-71. 